\title{
Erratum to: Hybrid attenuation model for estimation of peak ground accelerations in the Kutch region, India
}

\author{
A. Joshi • Ashvini Kumar $\cdot$ K. Mohan • B. K. Rastogi
}

Received: 15 August 2013/Accepted: 15 August 2013/Published online: 5 September 2013

(C) Springer Science+Business Media Dordrecht 2013

Erratum to: Nat Hazards (2013) 68:249-269

DOI 10.1007/s11069-012-0524-7

The following figure and text should be changed due to a handling error of the manuscript.

In Table 1, the coordinates of Mandvi are 22.84, 69.36, and the Morbi station should be removed from table as it is not in Fig. 2.

In Table 3, the magnitude of sub-events for each target event is $M_{\mathrm{w}} 4.5$ for magnitude less than and equal to 7.0 and 5.5 for target event of magnitude greater than 7.0. In this table, $m$ and $n$ denote position of nucleation point.

In Table 5, the depth for magnitude $7.7\left(M_{\mathrm{w}}\right)$ is $24 \mathrm{~km}$. The data for earthquake of magnitude $7.7\left(M_{\mathrm{w}}\right)$ have been taken after Iyengar and Raghukant (2004).

Page 262, 1st Para

In order to have size of sub-fault that represents earthquake of magnitude within range of applicability of developed attenuation relation, we have assumed magnitude $\left(M_{\mathrm{w}}\right)$ of sub-fault as 4.5 for target events of magnitude less than and equal to 7.0 and 5.5 for target events of magnitude greater than 7.0.

The online version of the original article can be found under doi:10.1007/s11069-012-0524-7.

A. Joshi · A. Kumar $(\bowtie)$

Department of Earth Sciences, Indian Institute of Technology Roorkee, Roorkee, India e-mail: ashvini_sharma2006@yahoo.co.in

A. Joshi

e-mail: anushijos@yahoo.co.in

K. Mohan · B. K. Rastogi

Institute of Seismological Research, Raisan, Gandhinagar 382009, Gujarat, India 


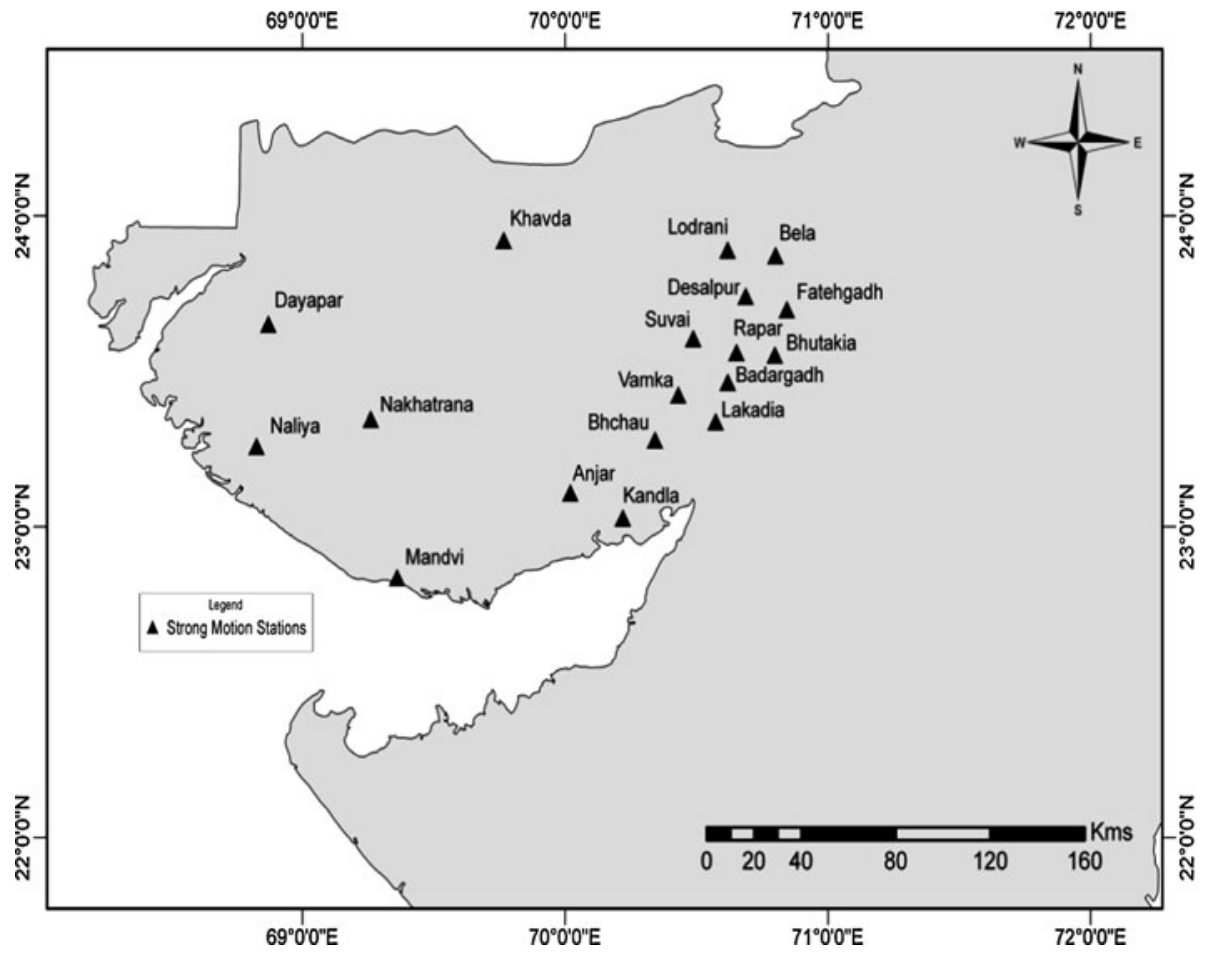

Fig. 2 Location of strong motion stations deployed in Kutch region of Gujarat by Institute of Seismological Research (ISR) 